\title{
EL PAPEL DE LOS RÍOS MUGA Y FLUVIÁ EN LA DETERMINACIÓN DEL TRASVASE DEL TER AL ÁREA METROPOLITANA DE BARCELONA
}

\author{
David Pavón Gamero \\ Departamento de Geografía. Universidad de Girona
}

\section{RESUMEN}

El trasvase del Ter ha sido fundamental para el abastecimiento de parte del área metropolitana de Barcelona. Sin embargo, un aspecto determinante para su ejecución ha pasado desapercibido: la existencia de unos ríos menores como la Muga y el Fluviá, vecinos del Ter, que facilitaron la toma de esa controvertida decisión. El artículo analiza su influencia y aporta una novedad en la temática que es la del enfoque territorial del trasvase, no tanto desde la óptica del entorno metropolitano o del conjunto de Cataluña, sino desde la perspectiva interna de los propios ríos gerundenses.

Palabras clave: trasvase del Ter, Muga, Fluviá, área metropolitana de Barcelona.

\section{ABSTRACT}

The Ter river transfer has been fundamental to the partial water supply of the metropolitan area of Barcelona. Nevertheless a determinant aspect to carry it out is hardly known: the existence of some smaller rivers as Muga and Fluviá, neighbouring of Ter river, that made easier to take this controversial decision. This paper analyses its influence and contributes with a novelty in the subject. This novelty is the territorial approach of the fluvial transfer, not from the point of view of the metropolitan area of Barcelona or of Catalonia as a whole, but the internal perspective of the rivers from Girona province.

Key words: The Ter river transfer, Muga, Fluviá, metropolitan area of Barcelona.

Fecha de recepción: mayo 2010.

Fecha de aceptación: febrero 2012. 


\section{INTRODUCCIÓN}

\section{Marco conceptual}

Los trasvases intercuencas (interbasin transfer o transbasin diversion) constituyen un eje de actuación infraestructural básico de la política hidráulica española durante buena parte del último siglo. Estas realizaciones pueden definirse como la transferencia de un volumen de agua específico desde una cuenca origen, entendida como excedentaria respecto a las demandas internas de sus aprovechamientos hídricos, a otra receptora, que se considera está en una situación de déficit para atender a los suyos propios. Así pues, la construcción de unos embalses para el almacenamiento de los caudales oportunos, junto con un canal o conducción que permita trasportarlos hasta el lugar deseado, fuera de los límites de la cuenca, se erigen en expresiones de la ingeniería que suelen ir aparejadas a los proyectos de trasvases. La controversia y la polémica serán elementos que acompañarán a las múltiples propuestas planteadas a lo largo del período y vendrán propiciadas por el debate sobre los beneficios y los costes asociados a su ejecución y explotación. Los efectos de este tipo de proyectos se analizan con detalle en obras de calado como el informe de la World Comission on Dams (Comisión Mundial de Represas, 2000). Ahora bien, no todo trasvase intercuencas ha de entenderse, necesariamente, como sinónimo de grandes infraestructuras o grandes impactos ambientales; dependerá del volumen y régimen de abastecimientos que se desee cubrir, del caudal y régimen natural del río donante, y de las distancias y obstáculos que haya que salvar. Incluso puede darse el caso de grandes infraestructuras hidráulicas dentro de una misma cuenca que generen más impactos que un trasvase (Arrojo y Gracia, 2000).

En un marco geográfico complejo como el que caracteriza la península ibérica y, bajo un discurso ideológico, económico, social y técnico de raíz regeneracionista favorable a las grandes obras hidráulicas, los trasvases acabarán presentándose como las piezas correctoras de los desequilibrios naturales climáticos e hidrográficos que estrangulan el desarrollo del territorio. Esta concepción se expresará, de manera diáfana y central, en el primer Plan Nacional de Obras Hidráulicas sistematizado que llegará de la mano del ingeniero Manuel Lorenzo Pardo en 1933. Así, al desequilibrio hidrológico producto del contraste entre los caudales disponibles en las vertientes atlántica y mediterránea, favorable a la primera, se contrapondrá un segundo desequilibrio de signo inverso. Éste consistía en la mayor potencialidad económica ligada al regadío de la vertiente mediterránea, siempre y cuando las dotaciones de caudal fuesen las suficientes (PNOH, 1933). Según los redactores del Plan, la solución al doble desequilibrio llegaría mediante la conducción de las aguas de las cuencas atlánticas a las mediterráneas a través de unas obras planificadas y ejecutadas por el Estado como máximo representante del interés general. Las áreas con escasez de agua sufrían una «injusticia de la naturaleza» y pedían al gobierno que acabase con tal «discriminación» mediante la «rectificación de este desorden natural» (Swyngedouw, 2007). Los trasvases se incorporan, de este modo, a la lógica y a las pretensiones de lo que por parte de varios autores se ha venido en denominar como el paradigma hidráulico español (Saurí y del Moral, 2001; Gorostiza, 2001; Pedregal, 2005; Benabent, 2006).

La concepción anterior será decisiva para entender parte de las realizaciones hidráulicas, especialmente durante el segundo franquismo, auspiciadas por un crecimiento económico 
intenso de los sectores agrario e industrial pero también para hacer frente al abastecimiento de aglomeraciones urbanas cada vez mayores. También será clave para comprender la concepción de las propuestas de anteproyecto y proyecto de Plan Hidrológico Nacional que gobiernos democráticos, de signo político contrapuesto, pondrán sobre la mesa, respectivamente, en 1993 y 2001.

El trasvase que centra este artículo tiene su razón de ser, precisamente, en el reto que supondrá dotar de los caudales suficientes a la expansión urbana de Barcelona y su zona de influencia. Aunque en este caso, por escala y por ubicación, no sea aplicable la oposición entre cuenca atlántica y cuenca mediterránea, sí tomará toda su intensidad el debate de las necesidades (y expectativas) hídricas de la cuenca cedente respecto a la receptora como argumento para oponerse a su ejecución.

\section{El caso del trasvase del Ter}

El trasvase del Ter al área metropolitana de Barcelona constituye una obra hidráulica fundamental para explicar el abastecimiento de una porción sustantiva de la capital catalana y de su entorno más inmediato en las últimas décadas. Son indudables los beneficios económicos y sociales que ha reportado para ese ámbito geográfico el hecho que, desde 1966, los caudales provenientes del río Ter, mediante una conducción de 85 kilómetros, permitan satisfacer parte de las necesidades y de las expectativas de su consumo hídrico. Las dimensiones del trasvase, en relación a las del río cedente y a las de la cuantía y diversidad de actividades que son atendidas por sus aguas, han convertido a este proyecto en pieza clave para entender la evolución y el dinamismo producido en el contexto metropolitano desde su puesta en funcionamiento. Ahora bien, las propias limitaciones de los parámetros del río, la proporción del volumen derivado respecto su caudal circulante y las posibilidades de desarrollo en la propia cuenca, han propiciado una polémica recurrente.

En la actualidad es plenamente vigente el debate sobre el papel a desempeñar por el Ter en el abastecimiento metropolitano y si el modelo de gestión de sus recursos hídricos ha de ser menos dependiente de este río. A este debate se han añadido elementos, en los últimos años, como las variables ambientales que consideran al río cliente del propio río, las posibilidades que ofrecen tecnologías como la depuración avanzada de aguas residuales o la desalación, el grado de eficiencia y ahorro en el consumo, la incidencia del cambio climático o las determinaciones de la Directiva Marco del Agua. Son unos ingredientes que han contribuido a la conformación de un nuevo escenario en que el «retorno parcial» de los caudales del Ter a la propia cuenca se plantea como una posibilidad más tangible. Tanto es así que la administración hidráulica catalana ha manifestado la voluntad de ir reduciendo gradualmente el volumen trasvasado en la medida que se vayan acometiendo nuevas medidas de gestión. Así, frente a los más de $190 \mathrm{hm}^{3}$ trasvasados anualmente de media durante la primera década del siglo XXI, se confía en reducir este volumen a los $130 \mathrm{hm}^{3}$ de 2013 y a los $115 \mathrm{hm}^{3}$ de 2015 . De acuerdo con el Plan de gestión del distrito de la cuenca fluvial de Cataluña, aprobado en 2010, el ámbito de abastecimiento del sistema Ter-Llobregat lo formaban más de 140 municipios con una población superior a los 4,5 millones de habitantes y una demanda urbana anual de unos $430 \mathrm{hm}^{3}$. Al Ter le correspondía satisfacer más del 40\% de esa dotación - un $38 \%$ al Llobregat y, el resto, a pozos y otros recursos - (Agencia Catalana del Agua, 2010a). 
El lugar preponderante del Ter en la geoestrategia hidráulica de un territorio que comprende incluso parte del área metropolitana de Barcelona ha dejado, en una segunda posición, a los cursos fluviales de la Muga y el Fluviá. Estos dos ríos, conjuntamente con el propio Ter, conforman la hidrografía básica de la provincia de Girona. Las características del relieve local han propiciado el discurrir paralelo y próximo de los tres ríos desde su curso medio hasta su desembocadura (ver figura 1). En el cuadro $\mathrm{n}^{\circ} 1$ se han incluido los principales parámetros de los tres ríos para su comparación. Se verifica la preponderancia del Ter sobre los otros dos ríos.

Cuadro 1

PRINCIPALES PARÁMETROS COMPARATIVOS DE LAS CUENCAS DEL TER, FLUVIÁ Y MUGA

\begin{tabular}{|c|c|c|c|}
\hline PARÁMETRO & Ter & Fluviá & Muga \\
\hline Superficie de la cuenca (en $\mathbf{k m s}^{2}$ ) & 3.010 & 993 & 702 \\
\hline $\begin{array}{l}\text { Superficie de la cuenca incluida en } \\
\text { la provincia de Girona }\left(\mathrm{en}^{\mathrm{kms}}{ }^{2}\right) \text { y } \\
\text { porcentaje sobre el total }\end{array}$ & $\begin{array}{c}1.880 \\
(62,46 \%)\end{array}$ & $\begin{array}{c}990 \\
(99,70 \%)\end{array}$ & $\begin{array}{c}694 \\
(98,86 \%)\end{array}$ \\
\hline $\begin{array}{l}\text { \% de la provincia de Girona } \\
\text { comprendida en cada cuenca }\end{array}$ & 31,83 & 16,76 & 11,75 \\
\hline Longitud del curso principal (en Km.) & 208 & 111,7 & 64,5 \\
\hline Precipitación media anual (en mm.) & 879 & 935 & 807 \\
\hline Precipitación media anual $\left(\mathrm{en}_{\mathbf{H m}} \mathbf{H}^{\mathbf{3}}\right.$ & 2.597 & 911 & 612 \\
\hline $\begin{array}{l}\text { Aportaciones superficiales medias } \\
\text { anuales }\left(\mathrm{en} \mathrm{Hm}^{3}\right)\end{array}$ & 844,94 & 264,41 & 149,63 \\
\hline Caudal medio $($ en m³/s) & $\begin{array}{l}17,15 \text { (en } \\
\text { Roda de } \\
\text { Ter; } 57 \text { años } \\
\text { registrados) }\end{array}$ & $\begin{array}{l}7,09 \text { (en } \\
\text { Esponellá; } \\
78 \text { años } \\
\text { registrados) }\end{array}$ & $\begin{array}{l}2,4 \text { (en } \\
\text { Boadella; } \\
84 \text { años } \\
\text { registrados) }\end{array}$ \\
\hline
\end{tabular}

Fuente: elaboración propia a partir de la Agencia Catalana del Agua (2005), Instituto de Estadística de Cataluña (2008) y Vehí, Brusi, Pallí y Roqué (1996).

Los intentos por ejecutar proyectos de gran obra hidráulica en los tres ríos a lo largo de los dos últimos siglos, se han de poner en consonancia con sus rasgos físicos: ríos con cursos independientes hasta su desembocadura, con una pluviometría suficientemente generosa especialmente en la cabecera y con un recorrido de orografía fracturada en la primera mitad de su curso pero con extensos llanos aluviales en su final. Esta combinación estimulará, por un lado, la realización de proyectos de presas en estrechos donde el relieve es más proclive y, por otro, a la conversión agrícola de los llanos fluviales en cultivos de regadío, a fin de incrementar su producción y rentabilidad. Respecto a este particular, cabe decir que los intentos por promover grandes proyectos de irrigación en el curso bajo de los ríos gerundenses se remontan, como mínimo, a la segunda mitad del siglo XIX. Si se analizan algunos de los discursos y voluntades expresadas por sus impulsores se deducirá que, al menos a nivel 
teórico, no serán ajenos a la aureola decimonónica que envolvió a la irrigación como pieza ineludible para superar una situación de pobreza y retraso crónicos (Borrell, 1857; Llauradó, 1884; Tutau, 1888; Coderch, 1900; González-Granda, 1930). La intensidad con la que, décadas después, las instituciones agrarias y económicas, en general, esgrimirán la expansión del regadío como elemento de reticencia al trasvase no se entendería sin estos antecedentes y es heredera de ellos. A la finalidad prioritaria de la irrigación en los proyectos hidráulicos se sumarán, desde el último tercio del siglo $\mathrm{XX}$, motivaciones como los abastecimientos urbanos y turísticos, llegándose a vivir episodios de conflictividad por la competencia entre usos del agua (Genís, 1987; Ribas y Saurí, 2002; Sastre, 2002; Ventura, 2004; Serra, 2009).

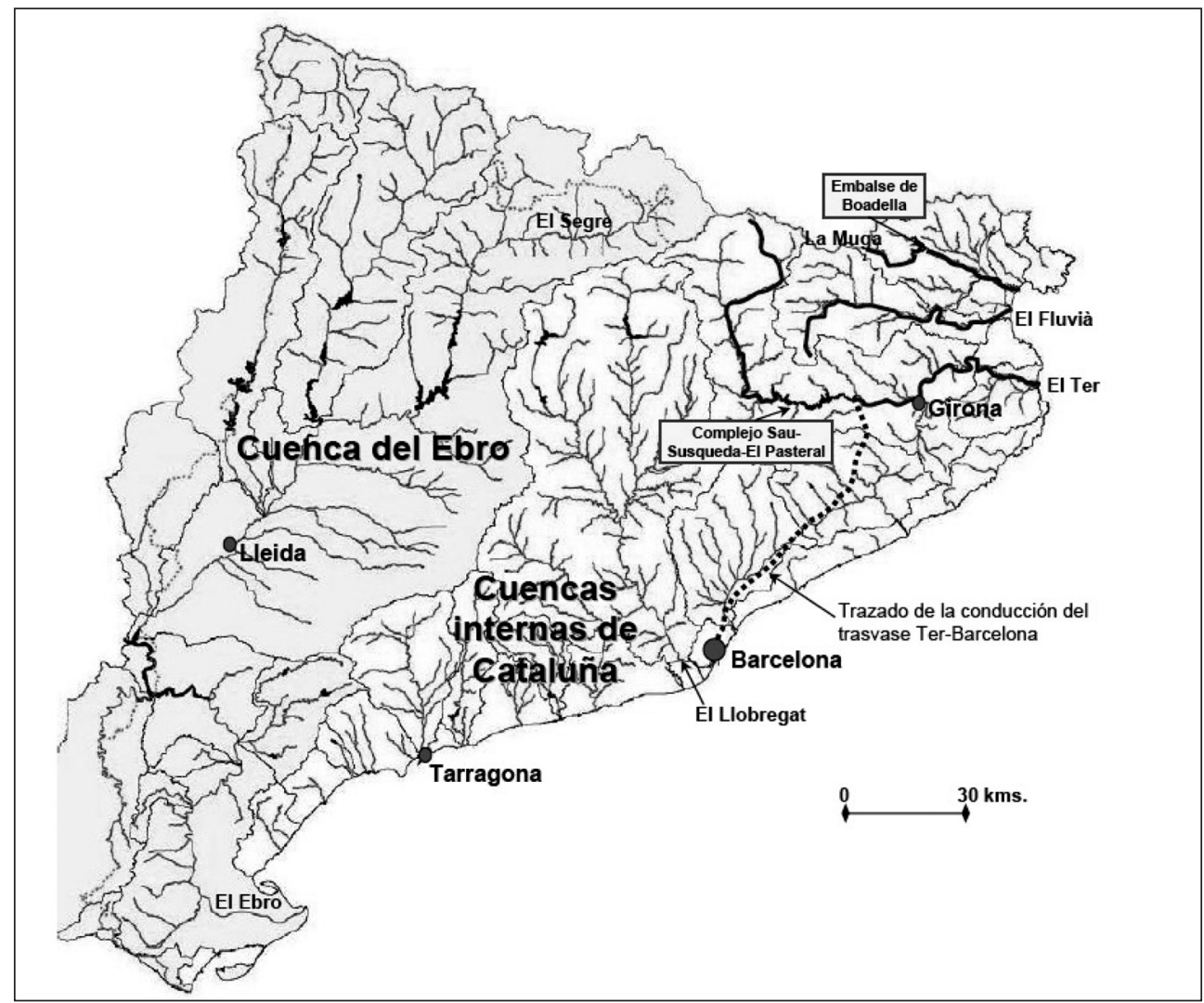

Cartografía de base: Agencia Catalana del Agua (2005). Elaboración propia.

En la determinación del trasvase del Ter resultó decisiva, aunque poco conocida, la existencia de los dos cursos menores anteriormente citados. Sin ella, muy probablemente, el Ter no habría llegado a alcanzar el protagonismo que adquirió desde la década de 1950-59. Por 
tanto, la importancia de la trayectoria seguida por estos dos ríos menores no sólo recaerá en las repercusiones que había de tener particularmente para cada una de sus cuencas, sino por la manera como podía incidir en el conjunto de los grandes ríos gerundenses entendidos como un sistema único de aprovechamientos. Las vicisitudes que ha atravesado la planificación hidráulica de las cuencas de la Muga y del Fluviá son más interesantes, si cabe, por las influencias que se han ejercido mutuamente ambos ríos y por la deriva contrastada y poco previsible que han acabado teniendo cada uno de ellos. Si el Fluviá fue el río que, debido a su mayor dimensión y centralidad geográfica, durante más tiempo fijó el grueso de las esperanzas y esfuerzos para promover una gran obra hidráulica que aprovechase sus caudales, sobre todo para el regadío de la llanura ampurdanesa, en cambio, será la Muga, el curso más modesto y periférico, el que finalmente ganará la partida en el terreno de las realizaciones.

Mediante la presente investigación se analiza la influencia muy poco conocida que tuvieron dos ríos menores como la Muga y el Fluviá en la determinación del trasvase del Ter, a la zona metropolitana de Barcelona y, un aspecto no menos relevante, como la geoestrategia hidráulica propiciada a escala provincial. Así, se aporta una novedad en la temática que es la del enfoque territorial del trasvase, no tanto desde la óptica del entorno metropolitano o del conjunto de Cataluña, como desde la perspectiva interna de los propios ríos gerundenses. A tal efecto, en el artículo se contextualizan los antecedentes y justificaciones previas del trasvase del Ter a Barcelona para proceder, posteriormente, a valorar el papel que jugaron aquellos dos ríos en la redacción del anteproyecto y proyecto que llevarían a la materialización de la obras durante la década de 1960-69. En la investigación se incluyen las argumentaciones contrarias esgrimidas desde la zona cedente y que suscitarán una controversia política y social de calado poco habitual en plena transición del primer al segundo franquismo. Antes de fijar las conclusiones, el estudio se detendrá en las repercusiones estrictas que tuvo a nivel de proyectos hidráulicos y en su derivada geográfica para las dos cuencas, distinguiéndose entre la fase previa a la aprobación del trasvase y la fase posterior.

\section{ANTECEDENTES Y CONTEXTUALIZACIÓN HISTÓRICA DEL TRASVASE DEL TER A BARCE- LONA}

El constante crecimiento que experimentan Barcelona y las poblacions más próximas a partir de la industrialización hará que las necesidades en el consumo de agua y la diversificación de sus usos se disparen y que se haga necesario buscar nuevas fuentes de suministro más abundantes y más alejadas de la ciudad. Si se considera sólo la capital, su número de habitantes se multiplicará casi por 7 entre 1877 y 1966. En 1877 Barcelona alcanza, por primera vez, la cifra de 250.000 habitantes; en 1966, cuando el agua del Ter llega a la ciudad, se situará en 1.700.000. El incremento en medio millón de habitantes en las dos décadas precedentes al inicio del trasvase del Ter es la confirmación de la ciudad condal como foco preeminente en la atracción de una segunda oleada de immigración, en el siglo XX, con origen especialmente en Andalucía y Extremadura. También del auge que vivirá la ciudad y su entorno metropolitano en la etapa del desarrollismo en el período 1960-75 (Voltes, 1966; Conillera, Llabrés y Parés, 1986; Aldomà, 2007).

Si se analiza el consumo de agua, el ritmo en el incremento todavía será más espectacular. Según datos de la antigua Sociedad General de Aguas de Barcelona, S.A., el suministro 
medio diario de consumo de agua a la ciudad pasó de los $57.500 \mathrm{~m}^{3}$, en 1910 , a los 369.124 $\mathrm{m}^{3}$, de 1959. Dicho de otra manera, en estos 50 años, el consumo de agua en la capital se multiplicó por 6,42. Para estos mismos años, el factor de multiplicación del número de habitantes fue de 2,62 (ver cuadro ${ }^{\circ}$ 2). En 1958 el abastecimiento a la ciudad de Barcelona se apoyaba en tres fuentes de abastecimiento: en primer lugar los pozos del Besós, que proporcionan unos $50.000 \mathrm{~m}^{3} /$ día, en segundo lugar, los del Llobregat, con unos $180.000 \mathrm{~m}^{3} /$ día y, en último término, la estación de superficiales del Llobregat (potabilizadora de Sant Joan Despí) capaz de tratar otros $180.000 \mathrm{~m}^{3} /$ día y cuyas instalaciones se estaban ampliando para alcanzar los $270.000 \mathrm{~m}^{3} /$ día (Compte, 1958).

Ante el incremento inexorable del consumo, la ciudad y su zona de influencia denotarán una preocupación acusada por recurrir a fuentes complementarias, ya desde antiguo. Si en el siglo X el agua llega del Besós (a la altura de Montcada) ${ }^{1}$, en 1871 parte de las aguas provendrán desde las captaciones de la zona de Dosrius (Maresme central); en 1881 las aportaciones subterráneas del Llobregat abastecen la villa de Sants y, en 1953, se obtendrá la primera concesión para su aprovechamiento superficial, que pasará a ser una realidad a inicios de 1955, con la entrada en servicio de la planta potabilizadora de Sant Joan Despí. A parte de esta trayectoria cabe citar, entre otras iniciativas, los dos concursos que abrió el Ayuntamiento, uno en 1896 (ampliado en 1899) y otro en 1910, para recibir proyectos de nuevas fuentes de abastecimiento. Si en el primero ya se presentaron propuestas de ríos tan alejados como la Noguera Pallaresa o el propio Ter, en el segundo se ofrecen 18 proyectos, incluyendo uno del río Valira, en Andorra (Ayuntamiento de Barcelona, 1912; Voltes, 1966; Latorre, 1995).

Cuadro 2

EVOLUCIÓN DEMOGRÁFICA Y DEL SUMINISTRO DE AGUAA BARCELONA (1910-68)

\begin{tabular}{|c|c|c|c|c|c|c|}
\hline Año & $\begin{array}{l}\text { Suministro medio } \\
\text { diario (en } \mathbf{m}^{3} / \text { día) }\end{array}$ & $\begin{array}{c}\text { Incremento en el } \\
\text { intervalo (en } \mathbf{m}^{3} / \text { día) }\end{array}$ & $\begin{array}{c}\% \text { de } \\
\text { incremento }\end{array}$ & Año & Habitantes & Incremento \\
\hline 1910 & 57.500 & -- & -- & 1910 & 587.411 & -- \\
\hline 1920 & 82.600 & +25.100 & $+43,65$ & 1920 & 721.508 & +134.097 \\
\hline 1930 & 127.000 & +44.400 & $+53,75$ & 1930 & 1.005 .565 & +284.057 \\
\hline 1940 & 168.800 & +41.800 & $+32,91$ & 1940 & 1.081 .175 & +75.610 \\
\hline 1950 & 230.300 & +61.500 & $+36,43$ & 1950 & 1.280 .179 & +199.004 \\
\hline 1959 & 369.124 & +138.824 & $+60,28$ & 1960 & 1.557 .863 & +277.684 \\
\hline 1968 & 531.147 & +162.023 & $+43,89$ & 1966 & 1.697 .102 & +139.239 \\
\hline
\end{tabular}

Fuente: Sociedad General de Aguas de Barcelona, S.A.

Si nos ajustamos al Ter, las pretensiones por conducir parte de sus aguas hacia Barcelona tampoco son nada nuevas. La primera referencia documental se remonta, ni más ni menos,

1 Se alude a la acequia construida por el conde Miró I (945-966), posiblemente de origen romano y que aún subsiste. De ahí el nombre «Rec Mir»y, posteriormente, «Rec Comtal» o «Sèquia Comtal» (Conillera, Llabrés y Parés, 1986). 
que a 1584 (Voltes, 1966). En aquel año, una delegación encabezada por el consejero primero de Barcelona, Pere Ferreres, efectuó un reconocimiento en las inmediaciones de la localidad ribereña de Sant Quirze de Besora (Osona), a unos $70 \mathrm{kms}$. al norte de Barcelona, y examinó la posibilidad de llevar las aguas, mediante una serie de minas, al río Congost y, desde allí, hasta el Besós. Su coste y las limitaciones técnicas de la época lo harían inviable pero dejaría su influencia en los intentos posteriores. A finales del XIX e inicios del XX se postularán intentos como el de Eusebi Pons (1868), el de Manuel Duran (1882), el de Manuel Bertrand (1910) y el de Horacio Echevarrieta, Isidoro Larrinaga y Eugenio Grasset (1910). En 1920, el reputado ingeniero Pere García Faria, reconocía abiertamente la insuficiencia del abastecimiento de Barcelona y el grave problema de salud pública que suponía. Así, exigía un estudio profundo y urgente de todas las posibles cuencas hidrográficas abastecedoras de la capital de manera que la Administración pudiera acometer, a corto plazo, obras hidráulicas tan satisfactorias como las que se habían venido ejecutando desde 1858 para el suministro de Madrid. Según García Faria, para una población de ambas ciudades próxima a 625.000 habitantes en 1917, mientras que Madrid disponía de una capacidad de reserva mediante embalses de $80 \mathrm{Hm}^{3}$, en el caso de Barcelona era inexistente. Si en Madrid, la capacidad de los depósitos de abastecimiento era de $681.000 \mathrm{~m}^{3}$, en Barcelona era sólo de $46.154 \mathrm{~m}^{3}$ (García, 1920).

Como antecedente más inmediato se ha de incluir, en una posición destacada, lo previsto en el Plan de Obras Públicas de 1935 impulsado por el gobierno autónomo de la Generalitat de Catalunya, durante la II República, y que incorporaba la derivación de una conducción desde el futuro embalse de Sau, no únicamente para abastecer Barcelona sino para la irrigación de 28.000 hectáreas en el llano del Vallés. El Plan incluía la construcción de dos embalses en la cuenca del río Muga (Boadella y Llobregat ${ }^{2}$ ), con una capacidad total de 96 $\mathrm{hm}^{3}$ para el riego de 21.000 ha. en el Ampurdán, y dos embalses en la del Fluviá (Argelaguer y Crespiá), con una capacidad total de $110 \mathrm{hm}^{3}$ para el riego de alrededor de 30.000 ha., también en el Ampurdán.

\section{EL PAPEL DE LA MUGA Y EL FLUVIÁ ANTE AL ANTEPROYECTO Y PROYECTO DE TRAS- VASE DEL TER A BARCELONA: EL PUNTO DE PARTIDA (1950-57)}

Ninguno de los proyectos anteriores se llevó a la práctica y, hasta la década de 1950, la ampliación de caudales para Barcelona se irá consiguiendo, fundamentalmente, perforando nuevos pozos en el freático del curso bajo del Llobregat. Años secos como 1945 y 1947-49 ocasionaron dificultades en el suministro y se planteó la necesidad de ampliar los caudales disponibles, con carácter inmediato, por medio de la utilización de las aguas superficiales del Llobregat. A la vez, no obstante, la Confederación Hidrográfica del Pirineo Oriental (C.H.P.O.) propuso al Ministerio de Obras Públicas (M.O.P.) la necesidad de atender en el futuro, por medio de aguas superficiales fluviales, grandes abastecimientos urbanos. Así pues, se concretó la conveniencia de diseñar un plan de utilización conjunta de los recursos hídricos de las cuencas del Pirineo Oriental en el que se tuviesen muy en cuenta las necesidades previsibles de suministro de Barcelona y de las localidades de su zona de influencia.

2 Se refiere aquí al principal afluente del río Muga por su izquierda, no al río barcelonés del mismo nombre. 
Por decreto de 31 de marzo de 1950, el M.O.P. ordena a la C.H.P.O. la redacción de un anteproyecto de abastecimiento de aguas a Barcelona y poblaciones de su zona de influencia, con caudales derivados del río Ter y otros caudales de menor relevancia. Constaría de un plan de obras escalonado que garantizase el suministro para un período de 50 años.

Como resultado de lo anterior se elabora un primer anteproyecto, suscrito en septiembre de 1950, por el ingeniero Joan Ma. Compte Guinovart en que se opta por la construcción de embalses reguladores que permitan asegurar las aguas para nuevos usos. La conclusión fundamental del anteproyecto es conseguir la regulación del Ter mediante la construcción de dos embalses, el de Sau $\left(177 \mathrm{hm}^{3}\right)$ y el de Susqueda $\left(70 \mathrm{hm}^{3}\right)$ para derivar a Barcelona $7 \mathrm{~m}^{3} / \mathrm{s}$ por una conducción de $85 \mathrm{kms}$ de longitud que recogería, al paso de los cursos fluviales del Montseny, $1 \mathrm{~m}^{3} / \mathrm{s}$ adicional. A partir de las proyecciones demográficas del Instituto Nacional de Estadística (I.N.E.) se consideraba que, con las aguas del Ter, las expectativas de consumo sólo estarían cubiertas hasta $1990^{3}$. Por eso se preveía, además, recurrir al Llobregat subsidiariamente aunque, de momento, no se fijaban las obras necesarias en la cuenca y sólo se indicaba la posibilidad de obtener, mediante su regulación, unos $4 \mathrm{~m} 3 / \mathrm{s}$. La mejor calidad del agua y la mayor cantidad a obtener priorizarán la solución del Ter.

Para hacerse una idea de lo que representaba la derivación de $7 \mathrm{~m} 3 / \mathrm{s}$, según los datos de la Agencia Catalana del Agua (año 2004), el caudal medio del Ter justo antes de la entrada al embalse de Sau, para 57 años aforados, ha sido de $17,15 \mathrm{~m}^{3} / \mathrm{s}$. Por tanto, lo que se pretendía derivar suponía el 40,81\% del caudal medio por segundo. En proyectos posteriores se llegará a proponer hasta $12 \mathrm{~m} 3 / \mathrm{s}$, el $70 \%$ del caudal medio. Al final, legalmente, se concederán 8 $\mathrm{m}^{3} / \mathrm{s}$, el $46,65 \%$ del caudal medio circulante en ese punto. De todos modos, recientemente, algunos autores han señalado la reducción de hasta un 40\% de las aportaciones del Ter a los embalses, desde la construcción del de Sau en 1963 (Armengol y Dolz, 2009), tendencia que mengua los márgenes de explotación de sus caudales.

El anteproyecto en cuestión fue aprobado por orden del M.O.P. de 25 de junio de 1954 . De acuerdo con el anteproyecto y los estudios formulados, en la misma orden se disponía la redacción del que habría de acabar siendo el proyecto definitivo. En este proyecto, ultimado en abril de 1956, se expresan las bases sobre las que se tendría que sustentar tanto el abastecimiento de agua potable a Barcelona y su zona de influencia, como los regadíos a desarrollar en la llanura ampurdanesa, gracias a las obras a ejecutar tanto en el río Muga como en el Fluviá (además del propio Ter). Esto denotará, como veremos más adelante, la voluntad a nivel técnico y político, que las realizaciones hidráulicas en los ríos vecinos del Ter sean suficientes para satisfacer las expectativas de desarrollo, sobre todo en materia de regadíos, en igual manera que si las aguas del Ter hubiesen permanecido íntegramente en su cuenca. Así, las bases del proyecto serán:

a) Regulación del río Muga con el embalse de Boadella $\left(62 \mathrm{hm}^{3}\right)$ y del Fluviá con el de Esponellá $\left(68,8 \mathrm{hm}^{3}\right)$ dedicando las aguas reguladas con absoluta preferencia a los regadíos (11.000 ha. en el caso de Boadella y 15.000 en el de Esponellá). En total,

3 Para el conjunto de Barcelona y de su zona de influencia se calcula una población superior a los 5 millones de habitantes para el 2000. Para entonces se supone una ratio de consumo de $250 \mathrm{l} / \mathrm{h} / \mathrm{d}$ para Barcelona y ligeramente inferior para su zona de influencia; en total, un consumo diario de 1,2 hm² en el año 2000 . 
26.500 ha. comprendidas en el llano del Ampurdán hasta llegar al margen izquierdo del río Ter.

b) Regulación de las aguas del Ter y de la riera Mayor con los embalses de Sau y Susqueda. Respecto al de Susqueda se plantea la opción que sea a través de un embalse pequeño $\left(70 \mathrm{hm}^{3}\right)$ o bien con uno grande $\left(250 \mathrm{hm}^{3}\right)$. En caso que se optase por la construcción del pequeño, para atender los regadíos del Gironés en años mínimos, se recomienda la construcción de dos pequeños embalses de uso exclusivo para el riego; uno en el río Llémena (pantano de Ginestar, con $12 \mathrm{hm}^{3}$ ) y otro en la riera de Amer (pantano de Amer, con $16 \mathrm{hm}^{3}$ ). Gracias a este escalonamiento de obras se pretendía asegurar el riego de 12.500 ha. en la comarca del Gironés y en el margen derecho del Ter para lo que serían necesarios unos $68 \mathrm{hm}^{3}$ anuales.

Para abastecer Barcelona y sus alrededores, se fijaban en $11 \mathrm{~m}^{3} / \mathrm{s}$ los derivados del Ter (y uno más de les rieras del Montseny), en vez de los 8 iniciales previstos en el anteproyecto, de manera que no fuese necesario recurrir al Llobregat. El nuevo proyecto se denominaría «de abastecimiento de agua potable a la ciudad de Barcelona y poblaciones de su zona de influencia. Obras de la primera etapa» y se aprobó técnicamente, por orden ministerial de 22 de julio de 1957. Mediante ella, además de la aprobación, se confería carta de naturaleza técnica y política para que se realizase la retahíla de infraestructuras hidráulicas antes citadas. Esta batería de obras pretendía también diluir los recelos de la sociedad gerundense ante el trasvase planteado y, ofrecer garantías que, pese a él, la provincia no se quedaría sin las infraestructuras necesarias para su desarrollo.

\section{EL PAPEL DE LA MUGA Y DEL FLUVIÁ Y LOS DICTÁMENES DE OPOSICIÓN AL TRASVASE DEL TER (1957-58)}

Desde el territorio de las cuencas afectadas directa o indirectamente por el trasvase se hicieron contrapropuestas. Como era de esperar, a diferencia de las anteriores, no basaban el eje de la solución, en conducir aguas desde el Ter. Serán unos documentos en que, más que analizar alternativas, se dedicarán a evaluar las consecuencias del trasvase y a justificar que todo el agua de los ríos gerundenses es necesario para garantizar el desarrollo de sus comarcas. Posiblemente, la muestra argumentada más nítida de rechazo al trasvase y al hecho que el aprovechamiento de los ríos Fluviá y Muga se ofreciese como compensación suficiente suya se plasmó en el documento de oposición, presentado por la Diputación de Girona, durante el período de información pública del anteproyecto y proyecto oficiales de trasvase, en verano de 1957. La propuesta fue elaborada, en septiembre de aquel año, en forma de dictamen, por tres ingenieros de ramas complementarias: Antonio del Águila (hidráulica), Joan Cabot (agronómica) y Lluís Thió (industrial).

El estudio parte del supuesto y pretende justificar, a diferencia de lo que han hecho los documentos patrocinados por la C.H.P.O., que todo el agua de los ríos Muga, Fluviá y Ter es necesario para cubrir los aprovechamientos agrarios y urbanos de la provincia de Girona. Se piensa que la derivación de las aguas del Ter afectaría gravemente a las expectativas de su desarrollo y que los caudales de la Muga y del Fluviá, por mucho que se regulen, no serán suficientes para sustituir los que se substraigan del Ter. Como alternativa, se propone que el abastecimiento de la capital y sus proximidades se efectúe con las aguas subterráneas 
y superficiales del Llobregat. Cuando éstas no sean suficientes, se podría recurrir a las del curso bajo del Ebro mediante una obra mixta para el riego del Campo de Tarragona, que se prolongase hasta Barcelona (ver figura 2).

En definitiva, para intentar evitar la llevada de aguas a Barcelona lo que hace el dictamen es justificar unos aprovechamientos intensivos y basados en grandes crecimientos (ya sea de regadíos o de abastecimientos urbanos) para sostener que todo el agua de los ríos gerundenses es imprescindible para cubrir los usos provinciales y que no existen excedentes posibles para derivar a Barcelona. Sobre este particular es bastante reveladora la intervención que efectuó el jefe de la sección económica de la Cámara Oficial Sindical Agraria (C.O.S.A.), Eduard de Ribot, en la reunión plenaria del 21 de marzo de 1959. Así quedaba recogido en su acta: «Sigue diciendo (refiriéndose a E. de Ribot) que las aguas sobrantes se derivarán a Barcelona, por lo que en nuestra mano está que no exista cantidad alguna por tal concepto; a cuyo objeto recomienda la constante intervención en las ramas proyectadas, el establecimiento de asociaciones de regantes y la puesta en marcha de entidades menores de regadios, así como de una entidad regante en cada cuenca, vinculadas a nuestra organización y que traten del trasvase de agua de una cuenca a otra (se refiere aquí al trasvase entre los propios ríos gerundenses)».

Figura 2

PROPUESTA DE ABASTECIMIENTO ÍNTEGRO DEL TER A LA PROVINCIA DE GIRONA REALIZADA POR SUS INSTITUCIONES (1957-58)

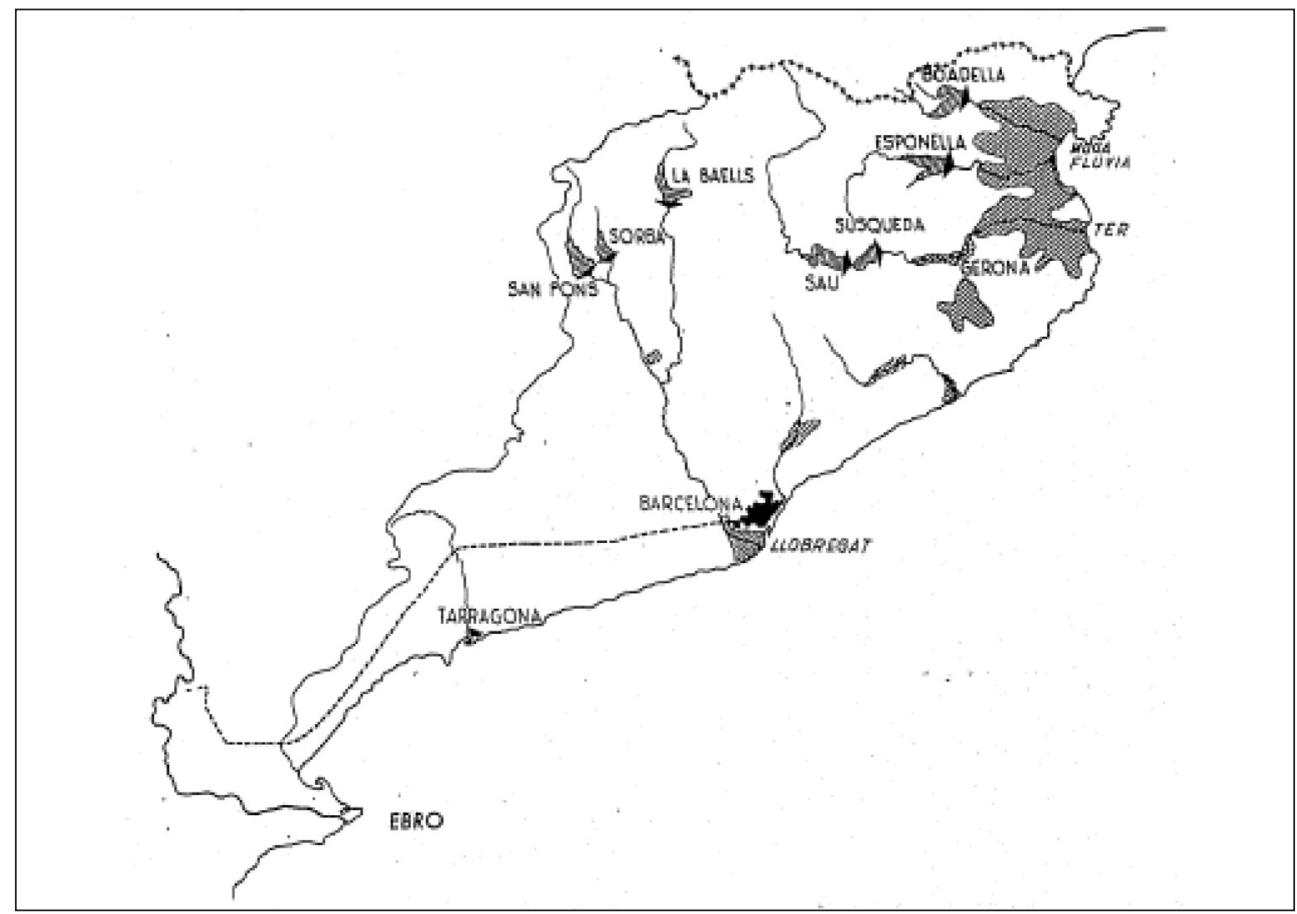

Fuente: Compte, J.M. (1958): «Abastecimiento de agua potable a la ciudad de Barcelona y poblaciones de su zona de influencia», Rev. de Obras Públicas, $\mathrm{n}^{\circ} 2.917,251-267$. 
Como alternativa al trasvase se propone que las aguas se queden en Girona y que, con ellas, se ponga en marcha un ambicioso plan de regadíos para conseguir cuatro grandes objetivos: fomento de la ganadería, la huerta, los frutales y la agroindustria. Estos cuatro puntos sintetizan los ejes sobre los que debía pivotar la transformación del sector agrario gerundense en la transición desde un modelo agrícola previo, basado en la autarquía y el autoconsumo, a otro más modernizado, más productivista y que quiere reforzar o abrir vías de comercialización hacia la metrópoli barcelonesa y el litoral turístico, fundamentalmente. A tal efecto se concretan seis grandes superficies regables con un total de 62.950 ha. La llanura del Ampurdán aspiraba a concentrar, según el informe, el 71,33\% de esa superficie, con 44.900 ha. De los nuevos regadíos, con las aguas de la Muga y del Fluviá (mediante los embalses respectivos de Boadella y Esponellá) se cubrirían 18.000 ha. mientras que con los dos del Ter (Sau y Susqueda) se haría lo propio con 39.000.

Sobre las propuestas realizadas en materia de suministro de regadíos dentro del proyecto de trasvase de la C.H.P.O., el dictamen es crítico y dice que se apoyan en caudales no seguros y en infraestructuras hidráulicas cuyas características no están resueltas: «Los caudales del río Ter son inciertos y optimistas (no es solo expresión nuestra), su regulación con el pantano de Susqueda grande no es segura, en la alternativa de Susqueda pequeño, el suplemento de caudales necesarios se propone obtenerlo mediante unos embalsitos no estudiados suficientemente - alude a los de Amer y Ginestar-, así como tampoco los cursos de agua en que habrían de establecerse; se cuenta con caudales regulados muy importantes del río Fluviá, cuyo embalse no puede considerarse siquiera como posible y finalmente se proyectan derivaciones en cursos de aguas del Montseny, cuyos regímenes hidráulicos no están suficientemente estudiados».

De acuerdo con los cálculos del estudio de la Diputación se asegura que la provincia de Girona precisa $661 \mathrm{hm}^{3}$ anuales, de los que $43 \mathrm{hm}^{3}$ (el 6,50\%) para el abastecimiento de Girona, de la Costa Brava y de otras poblaciones próximas al Ter, el Fluviá y la Muga; 460 $\mathrm{hm}^{3}$ (el 69,59\%) irían para los regadíos; $47,5 \mathrm{hm}^{3}$ (el 7,18\%) se dirigirían para satisfacer la circulación superficial en el caudal del Ter en los meses de invierno, cuando no se riega. Además no se pueden omitir los aprovechamientos existentes para la producción eléctrica. Por si fuese poco, se afirma que estas necesidades sólo se refieren a lo que queda de siglo pero que, en el futuro, podrían ir a más por el crecimiento demográfico, de las industrias y de otros regadíos (conclusión $7^{\mathrm{a}}$. del dictamen).

A parte del propio dictamen promovido por la Diputación, durante la información pública del proyecto de abastecimiento, se presentaron 384 escritos, la mayoría de oposición (García-Rives, 1958). Entre ellos había en contra el del Ayuntamiento de Girona, el de la Cámara Oficial de Comercio e Industria de Girona, el de la Cámara Oficial Sindical Agraria, los de 58 ayuntamientos, los de 44 Hermandades Sindicales de Labradores y Ganaderos, los de 19 sindicatos, los de propietarios de regadíos de 20 municipios y los de 24 industriales, entre otros (Llansó, 1958).

En la comarca de Figueres (Alt Empordà), atravesada enteramente por la Muga y punto por donde desemboca el Fluviá, el semanario oficialista «Ampurdán» no se quedaba atrás cuanto a la crítica del trasvase. En la portada del núm. 778, del 11 de septiembre de 1957, a hoja entera, se publicaba el artículo «Grave problema para el Ampurdán», firmado bajo el pseudónimo Clodianus (en alusión a un antiguo topónimo para designar al Fluviá): «El 
proyecto presupone la sustitución del agua del Ter, que ha de ser derivada hacia Barcelona, por las aguas del Fluviá y del Muga. Las aguas de estos ríos serán utilizadas para suplir la disminución que para el riego de la zona baja del primer río gerundense supondrá la pérdida de la que se derivará hacia Barcelona. [...] La utilización de las aguas del río Muga para otros menesteres que los previstos, ha de resultar en merma para los riegos que han de fecundar las tierras de nuestra comarca, o sea, de las 8.000 ha. calculadas en el Proyecto de Pantano de Boadella». El problema era percibido con más gravedad en el Ampurdán, donde gracias a su posición de entrada al resto de Europa y, con la perspectiva del incipiente Mercado Común, la comercialización de les nuevas producciones agrarias sería más fácil. La posibilidad de perjuicios llevará al Ayuntamiento de Figueres a presentar escrito de oposición.

Al primer dictamen emitieron su respuesta técnica, mediante diversos informes, los ingenieros de la C.H.P.O. Sin entrar al detalle de cada uno de ellos sí que, en líneas generales, considerarán excesivas las superficies de riego propuestas en el primer dictamen de la Diputación, también se generará una discusión sobre los caudales a garantizar para cada río y de sus usos respectivos. En las conclusiones propuestas por el ingeniero director de la C.H.P.O. para la información pública se asentarán algunos de los criterios que después se ratificarán en el Decreto del M.O.P. de 14 de noviembre de $1958^{4}$ determinando que de los caudales del río Ter regulados por los embalses de Sau y Susqueda, se destinase, con carácter preferente: $1 \mathrm{~m} / \mathrm{s}$ para el abastecimiento de Girona y poblaciones de la Costa Brava; otro caudal mínimo para el Ter, aguas abajo del Pasteral, que permita una circulación mínima de $3 \mathrm{~m}^{3} / \mathrm{s}$ al paso del río por Girona, y los caudales necesarios para la zona regable del Ter. De los caudales sobrantes del Ter, una vez deducidos los anteriores, se podría derivar hasta un máximo de 8 $\mathrm{m}^{3} / \mathrm{s}$ para el abastecimiento de Barcelona y de su zona de influencia (se rebajaban los 11-12 $\mathrm{m}^{3} / \mathrm{s}$ de propuestas anteriores). Que la preferencia se otorgue tanto a los abastecimientos como a los regadíos de Girona por encima del abastecimiento de Barcelona, al que sólo se dirigirán los «caudales sobrantes», será valorada por las principales instituciones gerundenses como un paso acertado pero insuficiente. El incumplimiento de este orden de prioridades será uno de los puntos más denunciados por regantes e instituciones locales con posterioridad al trasvase (C.O.S.A., 1968; Ferrer, 1998; Carmona, 2002; Illa, 2010).

En el informe del ingeniero director de la Confederación, además de lo ya apuntado, también se propondrá que se aprueben tanto el contestado expediente de información pública como el polémico proyecto de 1956 (y su anteproyecto) aunque con unas prescripciones. Si

4 Convalidado por la Ley 15/1959, de 11 de mayo. Será conocida popularmente como «Ley Vigón» por ser entonces, Jorge Vigón (1893-1978) ministro de Obras Públicas, cargo que ocuparía entre el 25-II-1957 y el 6-VII1965.

5 Desde su entrada en funcionamiento el criterio que ha prevalecido ha sido más bien el inverso, es decir, ofrecer unos niveles de garantía de los embalses para satisfacer prioritariamente el abastecimiento del entorno metropolitano; más aún en la medida en que las áreas receptoras han aumentado su tamaño demográfico, su urbanización y su demanda. Son las nuevas variables citadas en la introducción del artículo las que podrían recomponer la gestión de los caudales cedentes consiguiendo que una parte mayor de ellos permaneciese en la propia cuenca. Esta es la voluntad expresada por la administración hidráulica catalana. Conviene aclarar que, durante las décadas de vigencia del trasvase la cuenca origen como tal no ha recibido compensaciones económicas por parte del territorio beneficiario del trasvase. 
se procede a su lectura se percibirá el ánimo, por parte de la Confederación, de impulsar una serie de estudios y obras que calmen los recelos y la desconfianza de la sociedad local ante el proyecto inicial. Será una especie de medidas compensatorias que repercutirán, esencialmente, sobre las cuencas de la Muga y del Fluvà; en ellas se depositarán todas las esperanzas ante las «frustraciones» desencadenadas por el trasvase. Las más sobresalientes de ellas y que figurarán en las disposiciones aprobatorias serán:

a) Proceder en el plazo más breve posible a la construcción de los canales y redes de acequias de la zona regable del Ter y del resto de obras de regulación y de regadío de la provincia de Girona y, de manera inmediata, a las del embalse de Boadella en el río Muga.

b) Proceder con urgencia, por parte de la C.H.P.O., al estudio de los anteproyectos de ampliación de las zonas regables del Alt Empordà y la Selva que no figuran en los planes y proyectos anteriores.

c) Se dispone la creación de una Junta de desembalse en cada cuenca para la gestión de los respectivos embalses. La primera corresponderá al conjunto Sau-Susqueda-El Pasteral (Ter); la segunda a Esponellá (Fluviá) y, la tercera, a Boadella (Muga).

$\mathrm{Al}$ conocerse la respuesta contenida en los informes y la voluntad gubernamental de proseguir con el trasvase, la Diputación de Girona, conjuntamente con la C.O.S.A. y el Ayuntamiento de Girona presentarán, todavía, un «II dictamen de oposición», en junio de 1958, que ampliará el primero y reiterará los supuestos básicos en él contenidos. Pese a ello, el trasvase del Ter será aprobado por el Consejo de Ministros el 8 de septiembre de 1958 y por el posterior decreto del M.O.P. de 14 de noviembre, siguiendo las prescripciones técnicas ya apuntadas. Para certificar la aprobación y para crear la Junta Administrativa del Abastecimiento de Barcelona, el ministro de Obras Públicas, el teniente general Jorge Vigón, visitó la capital catalana el 25 de noviembre y, al día siguiente, Girona y Figueres, para anunciar la puesta en marcha de un plan de regadíos de 50.000 hectáreas $^{6}$.

\section{LA EJECUCIÓN DE LA GRAN OBRA HIDRÁULICA EN LAS CUENCAS DE LA MUGA Y DEL FLUVIÁ DESDE LA PERSPECTIVA DEL TRASVASE}

\section{La incidencia anterior a la aprobación del trasvase (hasta 1958)}

Con la aprobación del trasvase por las instancias técnicas y políticas correspondientes se asiste, en las tres cuencas que centran nuestro análisis, a una aceleración en el ritmo de redacción de los grandes proyectos hidráulicos así como de los regadíos sistematizados complementarios. Cuestión a parte es el grado de ejecución que se consiguió y que distó mucho de lo esperado si se compara con lo manifestado en 1958, cuando se da el visto bueno al trasvase. Ahora bien, la trayectoria de propuestas de gran obra hidráulica que se efectúa en

6 No deja de ser significativo que, en la crónica del diario oficialista «Los Sitios», no se haga una sola referencia a la oposición pública que la provincia había mostrado al proyecto. En cambio, paradójicamente, subrayó «la plena adhesión de los agricultores de esta provincia, representados por la Cámara Sindical Agraria rogando se transmitiera tal agradecimiento al Jefe del Estado por los beneficios que la provincia de Gerona, tan abandonada en otros tiempos, va a recibir en un futuro inmediato con la puesta en regadío de 50.000 hectáreas» (Los Sitios, 27-XI-1958). 
la Muga y, sobre todo en el Fluviá, no será nueva. Todo lo contrario, disponía de un largo recorrido que se remonta, como mínimo, a mediados del siglo XIX. Es entonces cuando en el Fluviá, por su mayor centralidad geográfica y capacidad de regulación, se concretan diversas propuestas fracasadas de grandes proyectos de irrigación de la mano de la iniciativa privada, que será atraída por los beneficios directos e indirectos que confiaba obtenerse con la consolidación y ampliación de los regadíos (Pavón, 2007).

En la década 1930-39, los proyectos previstos en el Fluviá atraviesan una etapa de reactivación, gracias fundamentalmente a la influencia ejercida por instituciones como la Cámara Agrícola del Ampurdán y de la recientemente creada Confederación Sindical Hidrográfica del Pirineo Oriental (año 1929). Es en 1930 cuando se culmina la redacción del primer proyecto de un gran embalse (denominado «de Crespiá») en la cuenca del Fluviá, con un volumen previsto de $65 \mathrm{hm}^{3}$ para el riego de 8.700 ha. en el Ampurdán. Tres años después se procederá a la constitución de la comunidad de regantes y, en 1935, a la colocación de la primera piedra. La Guerra Civil (1936-39) interrumpirá momentáneamente las obras, que se reactivarán una vez finalizada la conflagración y, con la declaración por parte del Consejo de Ministros del 6 de noviembre de 1941, como de «urgente ejecución» (BOE del 21 de noviembre de 1941, n 325, pág. 911). Cuando parecía que la gran obra de regulación del Fluviá contaba con el impulso definitivo, problemas geológicos por afloramientos de yeso, obligaron a la paralización y al abandono sorpresivo del proyecto en 1944.

El fracaso del embalse de Crespiá contribuirá a reconsiderar la opción aparcada, desde inicios del siglo XX, de construir un embalse en la cuenca del río Muga, más periférica y con menores posibilidades de regulación. A esta revalorización ya había contribuido, poco antes, el episodio de grandes inundaciones padecidas en octubre de 1940. La gravedad de sus consecuencias convencerá al aparato técnico de la construcción de una gran obra de regulación en el curso medio del río que, complementariamente, permitiese afianzar los regadíos del curso bajo. Así pues, en 1946, se concluye la redacción del primer proyecto de un gran embalse en el río Muga (denominado «de Boadella»), con una capacidad de 47,5 hm $\mathrm{hm}^{3}$ para el riego de unas 8.000 ha (Gete, 1946). En 1950, cuando se decide la elaboración del anteproyecto para abastecer a Barcelona con aguas del Ter, nos encontramos con una cuenca del Fluviá sin ninguna alternativa a las obras abandonadas del embalse de Crespiá (año 1944) y con una cuenca de la Muga que, aunque dispone de la redacción finalizada de un proyecto de embalse (año 1946), todavía no había sido aprobado técnicamente.

La decisión de elaborar el anteproyecto y posterior proyecto de trasvase tendrá, ya, unas primeras repercusiones técnicas para ambas cuencas. En el caso de la del Fluviá se reactivará el estudio de alternativas que permitan encontrar un nuevo emplazamiento para el futuro gran embalse del Fluviá. De entre ellas destacará, por su complejidad, el «Anteproyecto de regulación de los caudales del río Fluviá» (1953). Este anteproyecto pretendía la derivación de las aguas del Fluviá hasta un afluente próximo, el Ser, mediante la construcción de una galería de $11 \mathrm{~km}$. Allí se alzaría, para retenerlas, el embalse de San Miguel, con una capacidad prevista de $62 \mathrm{hm}^{3}$. Lo más relevante de este proyecto, desde el punto de vista que nos ocupa, es que su ejecución buscaba, precisamente, conducir una parte de las aguas del Fluviá hasta el río Ter, de manera que las del Fluviá pudiesen suplir a las que, teóricamente, se tenían que detraer desde aquel río hasta Barcelona. La pieza fundamental de esta propuesta de «fontanería hidráulica» era el citado embalse de San Miguel (toma su denominación de 
la cercana población del mismo nombre). Mediante su presa se confiaba en conducir anualmente hasta la cuenca del Ter unos $32 \mathrm{hm}^{3}$ para el riego de unas 4.300 ha. de su curso bajo asignadas, en un principio, al embalse de Sau (CHPO, 1953). Para conducir las aguas desde el embalse construido en el afluente del Fluviá hasta el Ter, se preveía una conducción de 26,89 kms. que vertería el caudal en el Llémena, afluente del Ter, donde se acumularía en otro embalse (ver figura $\mathrm{n}^{\circ} 3$ ). Con esta propuesta, tan atrevida como novedosa, la orientación del sistema de regulación Muga-Fluviá-Ter basculaba hacia el sur. La idea será que las aguas de la Muga y del Fluviá se dirijan al llano ampurdanés en sentido amplio e incluyendo un flanco más meridional, hasta el punto que se cubriesen con los sobrantes del Ter no incluidos en el trasvase.

La propuesta descrita, realmente, lo que pretende es solucionar con un trasvase interno entre ríos gerundenses las repercusiones generadas por otro trasvase, en este caso con un destino externo a las tres cuencas. En enero de 1957, los estudios geológicos del vaso del embalse desestimaron su construcción por la constitución del terreno y la existencia de filtraciones. Ese mismo informe, no obstante, ofrecía una tercera alternativa para construir el pretendido gran embalse del Fluviá. En ella se recuperaba el lecho del río tan solo a 500 metros aguas abajo del desestimado embalse de Crespiá por su constitución geológica diferente: «La

Figura 3

ANTEPROYECTO PARA LA REGULACIÓN DEL RÍO FLUVIÁ (1953)

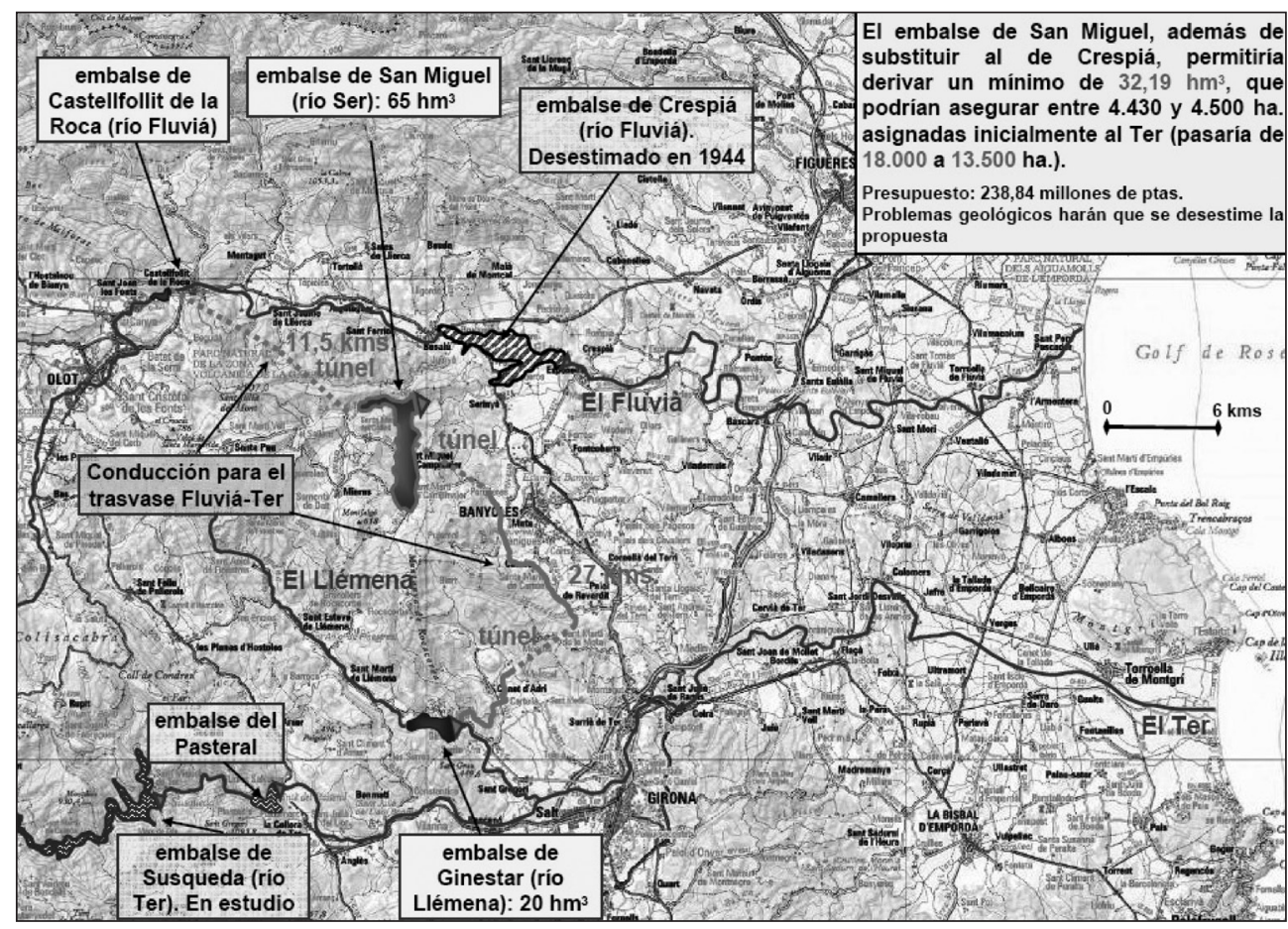

Base cartográfica: Mapa topográfico de Cataluña, E1:250.000, ICC, Barcelona, 2000. Elaboración propia. 
determinación de la gran fractura que constituye el borde occidental del bloque del Ampurdán, nos ha permitido elegir para situación de la presa que se propone en el río Fluviá, una cerrada a 500 metros aguas abajo de la abandonada de Crespiá» (CHPO, 1957). La nueva propuesta, denominada «embalse de Esponellá» será la que se incorporará para el Fluviá, en el decreto aprobatorio del trasvase de 1958.

Por lo que respecta a la cuenca de la Muga, el efecto parcial que tiene la redacción del anteproyecto de trasvase del Ter y de las concreciones posteriores, será el recrecimiento de la capacidad de embalse de Boadella. Así, en junio de 1954, se procederá a la aprobación técnica del proyecto de embalse que se ultimó en 1946. No obstante, con la aprobación técnica, se establece que será necesaria la confección de un proyecto de replanteo del mismo embalse que contemple la explotación conjunta con el río Fluviá y, no menos importante, que la capacidad útil del embalse aumente desde los 47,5 hasta los $62 \mathrm{hm}^{3}$ «para aprovechar al máximo las disponibilidades hidráulicas» (CHPO, 1954). Este objetivo se tenía que conseguir mediante la colocación de unas compuertas móviles en el aliviadero. En 1954 el aparato técnico es consciente que la situación incierta de la regulación del Fluviá, propiciada por el abandono del embalse de Crespiá, hacía que «el pantano de Boadella constituyera la parte principal del Plan conjunto para el regadio de la mayor extensión posible con aguas procedentes de los ríos Fluviá, Muga y afluentes» (CHPO, 1954). La elaboración de la nueva propuesta será finalizada en agosto de 1956 y debía de permitir el incremento de la superficie de riego hasta las 10.000 ó 12.000 ha.

\section{La incidencia posterior a la aprobación del trasvase (a partir de 1958)}

Si se compara el estado de las actuaciones de 1958, momento de la aprobación del trasvase, respecto la situación de 1950, que es cuando se decreta la realización del anteproyecto de trasvase, se aprecia que el período intermedio ha servido, en las cuencas de la Muga y del Fluviá, fundamentalmente, para imprimir un ritmo más vivo a la redacción de propuestas más sólidas que permitan su posterior ejecución. No obstante, aún no se había asistido al inicio efectivo de ninguna gran infraestructura hidráulica de calado que pudiese ser percibida como compensación al trasvase. Con la orden ministerial de 22 de julio de 1957 y la posterior aprobación política del trasvase, a finales de 1958, se incluirán medidas con la pretensión de finalizar la redacción de los proyectos hidráulicos pendientes, no sólo de los embalses sino de las redes de riego complementarias.

En el caso del Fluviá, el proyecto de embalse de Esponellá se acabó de redactar en diciembre de 1957 y fue aprobado técnicamente por orden ministerial de 3 de febrero de 1958; su expediente de información pública se aprobó mediante la pertinente Orden Ministerial, el 15 de julio de 1959. Este embalse estaba previsto para una capacidad de $68 \mathrm{hm}^{3}$ y para el riego de unas 18.000 hectáreas. En cuanto al anteproyecto de regadíos del Fluviá fue aprobado, igualmente, por medio de la respectiva orden ministerial, el 3 de mayo de 1960. Pese a esta rápida tramitación inicial y que comprende los dos años siguientes a la aprobación del trasvase, lo cierto es que, a partir de ese momento, los regadíos sistematizados del Fluviá entraron, a efectos prácticos, en una vía muerta y, ni el embalse ni la red de riegos sistematizados complementaria llegaron a efectuarse. Entre las posibles causas, a parte de la financiación de las obras o de la receptividad de los regantes a las condiciones planteadas, se 
ha de considerar la alternativa razonable que suponía el riego mediante aguas freáticas. Estudios posteriores revelarán un debate técnico y económico entre la conveniencia de apostar por unos riegos con aguas freáticas, o bien, mediante un embalse regulador en el curso medio del río (Comisaría de Aguas del Pirineo Oriental, 1971). El Plan Hidrológico de las cuencas internas de Cataluña (1985) ofrecía un balance de 4.672 ha. de regadíos no intensivos en el Bajo Fluviá, con un consumo anual de $18,69 \mathrm{hm}^{3}$. Dentro de este tipo de regadíos, según el informe, los del Bajo Fluviá eran los que disponían de unas dotaciones hídricas unitarias más elevadas de entre los existentes en las cuencas internas de Cataluña, con $4.000 \mathrm{~m}^{3} / \mathrm{ha} / \mathrm{año}$. Esta cifra suponía $1.500 \mathrm{~m}^{3} / \mathrm{ha} /$ año más que los riegos no intensivos del río Muga. Ante esta realidad cabría preguntarse hasta qué punto la no ejecución de los regadíos sistematizados del Fluviá ha de entenderse como un incumplimiento de los compromisos de 1958 o bien es atribuible a otras causas concurrentes que, con posterioridad, podrían haber desincentivado su transformación. La no ejecución de los proyectos del Fluviá, por su situación geográfica intermedia entre la cuenca de la Muga, al norte, y la del Ter, al sur, ha imposibilitado el tratamiento conjunto de los regadíos de las tres cuencas.

Por lo que respecta a la cuenca de la Muga, el embalse de Boadella sí superó la fase de proyecto, de forma que, en mayo de 1959, se produjo el inicio efectivo de las obras prolongándose por espacio de una década, hasta 1969. Por lo que a regadíos se refiere, el anteproyecto de zona regable fue ultimado a finales de 1958 y aprobado, técnicamente, en julio de 1959. El visto bueno al expediente de información pública llegó en noviembre de 1960. A diferencia del Fluviá, los regadíos de la Muga sí fueron incluidos dentro del programa específico de realizaciones comprendidas en los sucesivos Planes de Desarrollo Económico y Social; pese a ello su puesta en marcha se demoraba. El I Plan de Desarrollo (1964-67) preveía que, a su finalización, 17.288 hectáreas estuviesen transformadas en los regadíos del Ter y de la Muga; de ellas, 6.610 ha. en el Ter y 10.678 ha. en la Muga ${ }^{7}$. El caso es que, en 1967, un año después que las aguas del Ter llegasen a Barcelona, ni una sola hectárea de los regadíos previstos estaba en servicio. En noviembre de 1968, la C.O.S.A. de Girona editaba un informe con el título «Gerona y su agricultura». En este informe, la cámara analizaba los problemas que afectaban a la agricultura de la provincia, entre ellos el de los regadíos y el incumplimiento de la realización de su programa y el de las obras hidráulicas asociadas. Refiriéndose a las promesas del ministro Vigón durante su visita a Girona en 1958, se afirmará: «El propio titular del Departamento de Obras Públicas en aquellas fechas, con motivo de su visita a Gerona prometió que «...se irrigarían 37.000 ha. de terreno gerundense por de pronto, zona que se ampliaría posteriormente hasta llegar a las 50.000 ha., en fechas inmediatas». Transcurridos los diez años de la decisión y promesa, y cuando las aguas del Ter llegan ya a Barcelona, e incluso a la Maresma, ni una sola Ha. se ha puesto en riego en nuestra provincia.» (C.O.S.A., 1968).

Para agilizar la ejecución de los regadíos, el 21 de julio de 1966, coincidiendo prácticamente con la llegada de los primeros litros del Ter a Barcelona, se declaró de alto interés nacional la colonización de la zona regable de la Muga, acogiéndose así a las actuaciones, a

7 Los regadíos del Fluviá quedaron fuera de la previsión de las hectáreas a transformar por el hecho que, a diferencia de las cuencas de la Muga y del Ter, su embalse regulador no estaba ejecutándose al iniciarse el Plan. 
Figura 4

SECTORES DE LA ZONA REGABLE DEL RIOO MUGA. SUPERFICIE Y GRADO DE EJECUCIÓN

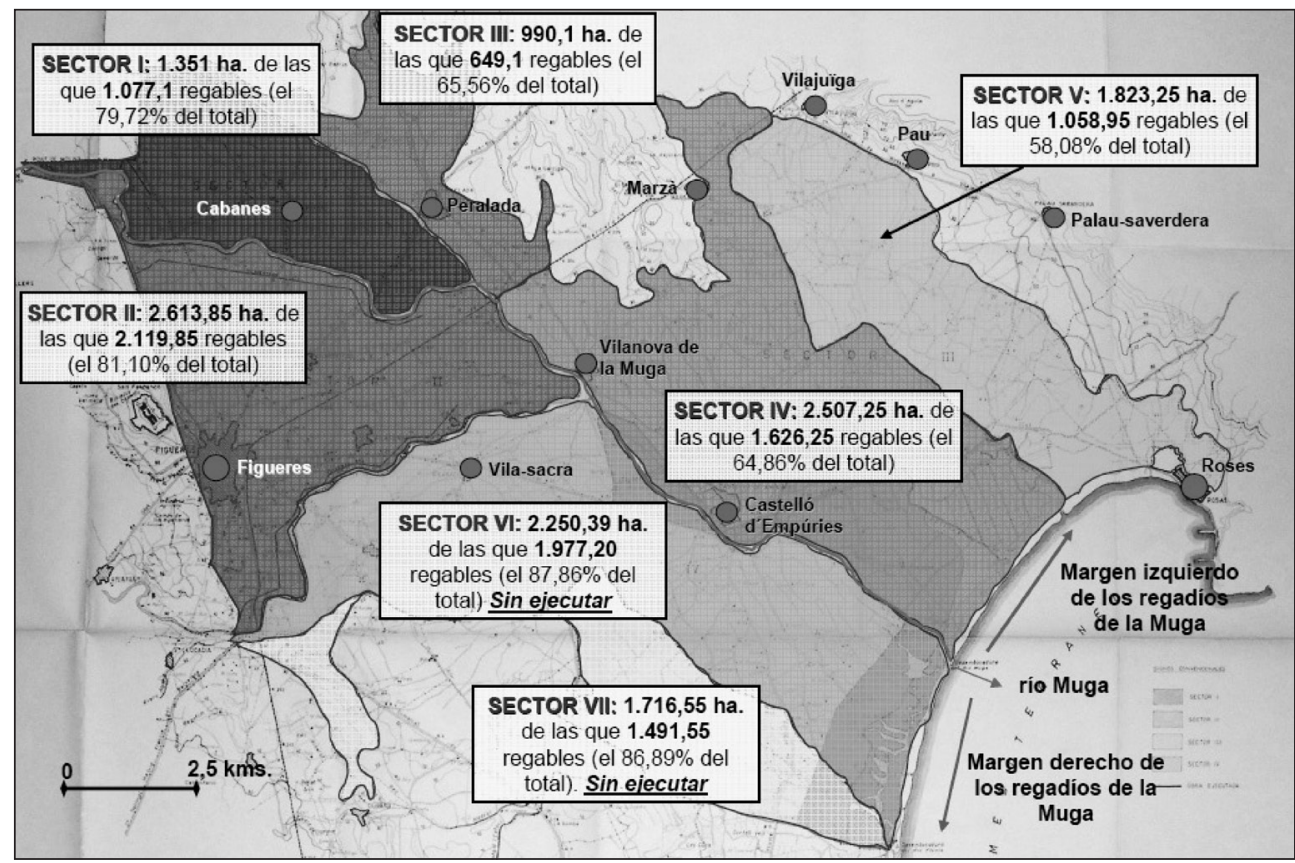

Base cartográfica: I.N.C., Plan General de Colonización de la zona regable del río Muga, Madrid, 1967.

Elaboración propia.

Aclaración: las superficies regables por sectores son las inicialmente previstas. Posteriormente han sido reducidas por dinámicas como el crecimiento urbanístico vivido, sobre todo, en la franja litoral y en la periferia de Figueres.

la financiación y a la legislación del Instituto Nacional de Colonización (I.N.C.) ${ }^{8}$. Aunque las previsiones eran las de transformar en regadío poco más de 10.000 hectáreas, la ejecución real afectó a 5 de los 7 sectores previstos mediante la aplicación de tres proyectos parciales que se pusieron en funcionamiento entre 1969 y 1975 (ver figura $\mathrm{n}^{\circ} 4$ ). La suma aproximada de hectáreas con riego sistematizado ascendió a unas 6.500 (2.100 del margen derecho y 4.400 del margen izquierdo). Cuestión a parte será la cuenca del Bajo Ter, el desarrollo de cuyos regadíos también fue declarado de alto interés nacional. Pese a la construcción de la presa-compuerta de la que se habían de derivar los canales principales de ambas márgenes (no construidos), la realidad es que la irrigación de esa zona se ha continuado fundamentando en las acequias históricas ya existentes. Respecto a la influencia del trasvase del Ter en las infraestructuras hidráulicas de los dos ríos, en el cuadro ${ }^{\circ} 3$ se ofrece una síntesis distinguiendo entre el período previo a su aprobación (año 1958) y el período posterior.

8 Decreto 2.108/1966, de 21 de julio (BOE n ${ }^{\circ}$ 193, 13-VII-1966). Tanto en la cuenca de la Muga como en la del Ter se elaboraron los respectivos planes de colonización en los que se incluyeron, entre otros aspectos, nuevos estudios agronómicos que actualizaban los datos de la década anterior. 
Cuadro 3

INFLUENCIA DEL TRASVASE EN LAS INFRAESTRUCTURAS HIDRÁULICAS DEL FLUVIÁ Y DE LA MUGA

\begin{tabular}{|c|c|c|}
\hline PERÍODO & FLUVIÁ & MUGA \\
\hline $\begin{array}{l}\text { Período previo a } \\
\text { la aprobación del } \\
\text { trasvase } \\
\text { (anterior a 1958) }\end{array}$ & $\begin{array}{l}\text { - Aceleración de la búsqueda de } \\
\text { alternativas para construir un gran } \\
\text { embalse regulador en la cuenca } \\
\text { frente al abandono del de Crespiá. } \\
\text { - Propuesta de trasvase Fluviá- } \\
\text { Ter con el embalse de S. Miguel } \\
\text { (1953) } \\
\text { - Redacción del proyecto de em- } \\
\text { balse de Esponellá (1957) }\end{array}$ & $\begin{array}{l}\text { - Replanteo del proyecto inicial } \\
\text { del embalse de Boadella y recreci- } \\
\text { miento de su capacidad (1954-56) }\end{array}$ \\
\hline $\begin{array}{l}\text { Período posterior } \\
\text { a su aprobación } \\
\text { (a partir de 1958) }\end{array}$ & $\begin{array}{l}\text { - Elaboración del anteproyecto de } \\
\text { regadíos del Fluviá (1959-60) } \\
\text { - Redacción de estudios y proyec- } \\
\text { tos complementarios tanto del em- } \\
\text { balse como de los regadíos } \\
\text { - Inclusión de los regadíos del } \\
\text { Fluviá en el I Plan de Desarrollo } \\
\text { (1964-67) } \\
\text { - Ejecución material nula del em- } \\
\text { balse y regadíos asociados }\end{array}$ & $\begin{array}{l}\text { - Ejecución del embalse de Boade- } \\
\text { lla (1959-69) } \\
\text { - Elaboración del anteproyecto de } \\
\text { regadíos de la Muga (1958-59) } \\
\text { - Inclusión de los regadíos de la } \\
\text { Muga en los planes de desarrollo } \\
\text { (1964-75) } \\
\text { - Declaración de alto interés na- } \\
\text { cional la colonización de la zona } \\
\text { regable de la Muga (1966). Inter- } \\
\text { vención del Instituto Nacional de } \\
\text { Colonización. } \\
\text { - Ejecución parcial de los sectores } \\
\text { irrigables previstos (1969-75) }\end{array}$ \\
\hline
\end{tabular}

Fuente: elaboración propia.

\section{CONCLUSIONES}

El aprovechamiento de dos ríos periféricos como los tratados (Muga y Fluviá), aparentemente había de tener unas repercusiones que no superarían la escala local. Sin embargo, al ser presentados como compensación a la desviación de los caudales del Ter, permitieron la ejecución de uno de los trasvases más relevantes que serán materializados a nivel español para atender a una aglomeración urbana de primer orden. El trasvase del Ter, por el momento en que se ejecuta y por su finalidad primordial, ha de entenderse como síntoma que vaticina la fase de fuerte crecimiento económico que se vivirá durante el desarrollismo de 1960-75. También como una de las consecuencias de la consolidación de un fenómeno de urbanización intenso hasta tal punto que, dibuja ya, inequívocamente, a la área metropolitana más destacada siguiendo de cerca a la de Madrid; unas áreas metropolitanas que necesitarán recurrir a fuentes de abastecimiento más alejadas para afrontar una demanda hídrica que se acrecenta y diversifica. Pese a ello, a diferencia de Madrid, en el caso de Barcelona obras 
hidráulicas de magnitud similar para el suministro urbano no se emprenderán hasta casi un siglo después. En Madrid, no obstante, no hizo falta recurrir a trasvases de cuencas hidrográficas ajenas a la propia capital, si se toma como límite a la del Tajo?.

Como en muchas otras zonas del territorio español, el regadío fue el motivo que centró la justificación para redactar grandes proyectos hidráulicos para los ríos gerundenses desde la segunda mitad del siglo XIX. Sin embargo, hará falta esperar a que una demanda hídrica urbana y externa a sus cuencas sea lo suficientemente acuciante para que comiencen a plasmarse las obras, pasando por delante incluso de los propios regadíos. Ahora bien, la conducción del Ter hacia Barcelona y su zona de influencia, no era ninguna propuesta nueva y las pretensiones para hacerla realidad, tal y como ya se ha puesto de relieve, arrancan de lejos. La diferencia residirá en que, a partir de la década de 1950, se estará en condiciones de concretarla. El trasvase del Ter, paradójicamente, servirá para reactivar la construcción de obras hidráulicas en las otras dos cuencas, en parte como vía para compensar el agravio que representaba la llevada de aguas y, por tanto, como forma de mitigar el sentimiento de rechazo y neutralizar la oposición social generada en las tierras de Girona.

La orden ministerial de julio de 1957, que aprobaba técnicamente el proyecto de trasvase, daba luz verde a la redacción urgente de una batería de estudios facultativos tanto de grandes embalses como de sus respectivas áreas de regadíos. Sin el Fluviá ni la Muga, probablemente, nunca se habría planteado la «Solución Ter» hacia Barcelona, no tan solo por una fría cuestión de caudales, sino porqué no habría existido ningún tipo de «comodín» capaz de absorber la presión generada en contra del proyecto. El argumento del aprovechamiento hidráulico máximo del Fluviá y de la Muga, o sea, sin excedentes, permitió ofrecer una justificación para su rechazo por parte de las principales instituciones provinciales, aunque poco efectiva y convincente para neutralizarlo. Las contrapropuestas efectuadas por ellas, en la línea que Barcelona se abasteciese con aguas del Ebro, tampoco fructificarán. La orden ministerial de julio de 1957, con las derivadas que se desprenden de ella, además de toda la presión social creada, ayudará a entender por qué, muy poco tiempo después, en 1960, ambas cuencas dispondrán de los respectivos proyectos de embalse y de los respectivos anteproyectos de las zonas regables. Más aún, en el caso de la cuenca de la Muga, el embalse de Boadella ya se encontraba en fase de obras. Por tanto, parecía más cercana que nunca la ejecución material completa de las grandes infraestructuras hidráulicas y de los regadíos sistematizados asociados. A corto plazo, esta progresión aparente se revelaría como puro espejismo.

Con el trasvase se rompe, definitivamente, en el ámbito de los tres ríos gerundenses señalados, el principio de relación entre obra hidráulica proyectada y cuenca hidrográfica destinataria. Este hecho arrastrará, por proximidad, a las dos cuencas vecinas septentrionales del Ter con diversas repercusiones. En primer lugar, el intento de planificación unitaria con los recursos hídricos de las tres cuencas como si se tratase de una sola. En segundo lugar, las propuestas constructivas que se formularán para la Muga y el Fluviá se realizan pensando en liberar los máximos caudales del Ter para dirigirlos, con garantías, a Barcelona y sus alrededores. Por ese motivo, ambas cuencas adquieren un valor estratégico que va mucho más allá de la escala local (como había pasado hasta entonces). En tercer lugar, la orientación teórica

9 Pese a que todo el sistema de suministro se abastece de recursos afluentes al Tajo, su red ha exigido la interconexión de 7 cuencas fluviales distintas, que incluyen los trasvases de los ríos Sorbe y Alberche. 
que tomará el sistema de obras hidráulicas para la irrigación del Empordà, en relación a las zonas beneficiarias, basculará hacia al sur.

La nula ejecución de las obras de regulación e irrigación en la cuenca del Fluviá dará al traste con el grueso de los supuestos teóricos anteriores ya que, por su ubicación geográfica central respecto a la Muga, al norte, y el Ter, al sur, se imposibilitará la planificación unitaria que se preconizaba. Por la misma causa quedará sin efecto la idea de orientar hacia el sur todo el sistema de regadíos. Sin embargo, la no construcción de ninguna gran infraestructura hidráulica en el Fluviá, ha convertido a este río en el mayor de las cuencas internas catalanas con un régimen de caudales más naturalizado.

En otro orden de cosas, por los antecedentes de que se dispone, el escenario estratégico que se dibuja entre las tres cuencas, a raíz del trasvase del Ter, a finales de la década de 1950, es factible creer que se hubiese avanzado a inicios de la década de 1940 o incluso a finales de la década de 1930 bajo algunos supuestos que nunca se podrán corroborar. Estos supuestos habrían pasado, primeramente, por la aprobación del Plan de Obras Públicas de la Generalitat republicana en el año 1935 con las previsiones de regadíos y de abastecimientos que se adjudicaban para los tres ríos gerundenses (incluyendo el trasvase de aguas del Ter para Barcelona y el Vallés). En segundo lugar, por la no interrupción traumática que representó la Guerra Civil de 1936-39 desde una perspectiva política, técnica y de tramitación administrativa. Finalmente, por la ausencia de la profunda recesión económica que se vivió con posterioridad a la Guerra Civil y que se agravó por una situación de aislamiento internacional, hasta inicios de la década de 1950. Dicho de otra manera, en un hipotético escenario de expansión económica a finales de la década de 1930 y en la siguiente, es factible que la progresión en el aumento de las demandas hídricas para Barcelona y su entorno hubiese sido más acelerada (asociadas al desarrollo industrial, a la intensificación agrícola y a unos abastecimientos urbanos que habrían de atender una mayor diversidad de usos). Esto justificaría poner sobre la mesa, ya entonces, la solución que se acabó adoptando 20 años después. De hecho, la comparativa que dibuja el ingeniero García Faria entre los abastecimientos de Madrid y Barcelona en 1920, dos ciudades con dimensiones demográficas similares, certifica que en el caso de Madrid grandes obras hidráulicas para el suministro urbano, como embalses y sus conducciones asociadas, empezaron a construirse ya, como mínimo, en 1850-59, un siglo antes que en el caso de Barcelona.

En sentido contrario, podría cuestionarse cómo habría condicionado la marcha de los acontecimientos el mantenimiento de un régimen democrático el cual es de esperar que hubiese gestionado, de diferente manera, la oposición que se produjo. Una oposición, por cierto, bastante excepcional para la época y sus circunstancias, más aún si se toma en consideración que fueron las propias instituciones políticas y corporativas las que la encabezaron.

La aprobación del trasvase estimulará la redacción y la ejecución parcial de proyectos de gran obra hidráulica con una clara orientación hacia el regadío, tanto en la cuenca de la Muga como en la del Fluviá. No obstante, si se compara lo previsto en relación con el ritmo de lo ejecutado y, especialmente, con la progresión mucho más ágil que experimentaron las obras del trasvase, se habrá de concluir que lo cumplido distó notablemente de lo prometido. De todos modos se tendría que relativizar la influencia real que tuvo lo no ejecutado si se quiere entender, simplemente, como incumplimiento de las compensaciones que se anunciaron. Es decir, se tendría que valorar hasta qué punto las infraestructuras no ejecutadas, sobre todo en 
cuanto a regadíos se refiere, es atribuible al mero incumplimiento de lo prometido o bien es achacable a otras causas concurrentes. De manera paralela también habría que cuestionarse en qué medida la no ejecución de las obras previstas han condicionado o no los cambios o mejoras que se esperaban con ellas.

* El autor agradece las observaciones preliminares efectuadas por la Dra. Anna Ribas.

\section{BIBLIOGRAFÍA Y DOCUMENTACIÓN BÁSICA CONSULTADA}

AA.VV. (1969): II Plan de Desarrollo Económico y Social. Madrid. Imprenta Nacional del B.O.E.

Actas de las Asambleas plenarias de la C.O.S.A.: del 4-VII-1953 al 28-XI-1959 y del 28-XI1959 al 16-XII-1972. Archivo de la Cámara Agraria de Girona.

AGENCIA CATALANA DE L'AIGUA - A.C.A.- (2005): Caracterització de masses d'aigua i anàlisi del risc d'incompliment dels objectius de la Directiva Marc de l'Aigua (2000/60/ce) a Catalunya (conques intra i intercomunitàries). Barcelona.

A.C.A. (2010a): Gestió de l'aigua i cabals del Ter 2009, hoja informativa.

A.C.A. (2010b): Pla de gestió del districte de conca fluvial de Catalunya. Barcelona.

ALDOMÀ, I. (2007): La lluita per l'aigua a Catalunya. De l'ús i abús a la gestió integral (1900-2007). Lleida. Pagès editors.

ARMENGOL, J. y DOLZ, J. (2009): «L'abastament d'aigua a Catalunya i la seva garantia». Nota d'Economia, Revista d'economia catalana i de sector públic, n 93-94, 127-139.

ARROJO, P. y GRACIA, J.J. (2000): Los trasvases del Ebro a debate, Nueva Cultura del agua. Serie informes, 2000/8. Bilbao. Bakeaz.

ASESORÍA GEOLÓGICA DE OBRAS PÚBLICAS (1944): Informe sobre las condiciones geológicas de la cerrada del pantano de Crespiá, Madrid, Fondo de Obras Públicas, firma: 14.555. Archivo General de la Administración (en adelante AGA).

BENABENT, M. (2006): La Ordenación del Territorio en España. Evolución del concepto y de su práctica en el siglo XX. Sevilla. Junta de Andalucía y Universidad de Sevilla.

BORRELL, F. (1857): Memoria del canal del Norte de Cataluña, 1857. Fondo de Obras Públicas, AGA, caja n ${ }^{\circ} 35.287$.

CARMONA, R. (2002): «Els regants denunciaran l'incompliment de la llei que només permet dur l'aigua del Ter cap a Barcelona si en sobra», Girona, periódico El Punt, 18-VI-2002.

CARRERAS, J. Mª, BERNAT, J. y CAMARASA, J.Ma . -introducción- (1982): Pla General d'Obres Públiques (1935). Barcelona. Departament de Política Territorial i Obres Públiques

C.H.P.O. (1985): Plan Hidrológico del Pirineo Oriental. Redacción estudio. Bases técnicas, Barcelona, Dirección General de Obras Hidráulicas.

CLODIANUS (1957): Grave problema para el Ampurdán, Ampurdán, nº 778, Figueras, 11-9-1957.

CODERCH, R. (1900): Plan General de canales y pantanos. Datos relativos a la cuenca del río Fluviá, División de trabajos hidráulicos de la cuenca del Ebro y vertientes de los Pirineos Orientales, 1900. Fondo A.C.A., sigt. n 448, caja (u.i.): 38. Arxiu Nacional de Catalunya (en adelante ANC). 
COMISARÍA DE AGUAS DEL PIRINEO ORIENTAL y SERVICIO GEOLÓGICO DE OBRAS PÚBLICAS (1971): Estudio de los recursos hidráulicos totales del Pirineo Oriental. Informe hidrogeológico sobre la zona aluvial de los ríos Fluviá-Muga. Barcelona. D.G.O.H.

COMISIÓN DE TRANSFORMACIÓN DE REGADÍOS: Transformación en regadios. Madrid. Comisaría del Plan de Desarrollo Económico y Social.

- Anexo al Plan de Desarrollo Económico y Social (1964 a 1967). Año 1964.

- Anexo al Plan de Desarrollo Económico y Social (1968 a 1971). Año 1968.

COMISIÓN PARA EL ABASTECIMIENTO DE AGUAS DE LA CIUDAD (1912): Dictamen emitido por la Comisión para el Abastecimiento de Aguas de la Ciudad. Barcelona. Imprenta de Henrich y Cia, Córcega, 348, 1912.

COMISIÓN TÉCNICA MIXTA (1976): Plan Coordinado de Obras de la zona regable del río Muga (Gerona), Gerona, IRYDA y C.H.P.O. Archivo del Ministerio de Agricultura en Girona.

COMPTE, J. Mª (1958): «Abastecimiento de agua potable a la ciudad de Barcelona y poblaciones de su zona de influencia». Revista de Obras Públicas, n $^{\circ} 2.917,251-267$.

COMPTE, J. Ma . (1966): «Nuevo abastecimiento de agua a Barcelona». Revista de Obras Públicas, $\mathrm{n}^{\circ} 3.017,701-727$.

CONILLERA, P., LLABRÉS, A. y PARÉS, M. (1986): L'aigua a Barcelona, col·lecció Descobrir el medi urbà, $\mathrm{n}^{\circ}$ 4. Barcelona. Ajuntament de Barcelona.

C.O.S.A. (1968): Gerona y su agricultura, Gerona, Cámara Oficial Sindical Agraria.

DE CAMPS, J. (1976): El Ter. Barcelona. Destino.

DEL ÁGUILA, A., CABOT, J. y THIÓ, L. (1957): Oposición de la provincia de Gerona al anteproyecto y proyecto de desviación de las aguas de las cuencas de los ríos Ter y Tordera, Gerona, Diputación Provincial de Gerona

FERRER, F. (1998): «El transvasament d'aigües a Barcelona» en La Punxa, n 27, Girona, Col·legi d'aparelladors i arquitectes tècnics de Girona, 16-19.

GARCÍA, P. (1920): «Deficiencias de los abastecimientos de agua de las poblaciones españolas. Examen especial de los de Madrid y Barcelona». Revista de Obras Públicas, $\mathrm{n}^{\circ}$ 2.315-16, 55-74.

GARCÍA-RIVES, A. (1958): «Resumen del informe del ingeniero jefe Sr. García-Rives» en ORDIS, J., CABOT, J., NOGUERA, J.M . y VIDAL, M. (1958), II Dictamen de oposición presentado por la provincia de Gerona en el trámite de vista del expediente administrativo del anteproyecto y proyecto de abastecimiento de Barcelona con aguas del río Ter, Gerona, Diputación Provincial, Cámara Oficial Sindical Agraria y Excmo. Ayuntamiento, 12-13.

GENÍS, N. (1987): L’aigua a la badia de Roses. Girona. Consorci de la Costa Brava.

GETE, A. (1946): Proyecto de pantano de Boadella, Barcelona. C.H.P.O. Fondo. A.C.A.; firma. ${ }^{\circ}$ 499, caja (u.i.): 44. ANC.

GONZÁlEZ, M. (1930): Pantano de Crespiá, Barcelona. CSHPO. Fondo de Obras Públicas; topogr.: 24; caja núm.: 14.561. AGA.

GONZÁLEZ-GRANDA, E. (1930): Conferencia sobre el pantano del Fluviá. Publicaciones de la Confederación Sindical Hidrográfica del Pirineo Oriental, VIII, Barcelona, C.S.H.P.O. 
ILLA, N. (2010): «Els regadius del Baix Ter. Necessitats hídriques» en GAYA, J., L’aigua a les comarques gironines. Girona, Taula d'enginyeria de les comarques gironines, 69-70.

I.N.C. (1967): Plan General de Colonización de la zona regable del río Muga. Madrid. Dirección General de Colonización y Ordenación Rural (Ministerio de Agricultura). Archivo de la delegación del Ministerio de Agricultura en Girona.

LATORRE, X. (1995): Història de l'Aigua a Catalunya. Premià (Barcelona). L'Abecedari.

LORENZO, M. (Dir.) (1933): Plan Nacional de Obras Hidráulicas. Madrid. Reedición del Centro de Estudios y Experimentación de Obras Públicas, 1993.

LLANSÓ, J. (1958): «Resumen del informe del ingeniero Sr. Llansó referente a los restantes escritos presentados en la información pública» en ORDIS, J., CABOT, J., NOGUERA, J.M . y VIDAL, M. (1958), II Dictamen de oposición presentado por la provincia de Gerona en el trámite de vista del expediente administrativo del anteproyecto y proyecto de abastecimiento de Barcelona con aguas del río Ter. Gerona. Diputación Provincial, C.O.S.A. y Ayuntamiento, 9-10.

LLAURADÓ, A. (1884): Tratado de aguas y riegos. Madrid. Imprenta de Moreno y Rojas ( $2^{\mathrm{a}}$. edición corregida y aumentada).

MUNTANER, J. M. (Dir.) (1973): Los regadios de Gerona en el desarrollo provincial. Gerona. Servicio de Publicaciones de la Caja de Ahorros Provincial de la Diputación de Gerona.

MUÑOZ, V. (Dir.) (1935): Pla d'Obres Públiques, Barcelona, Generalitat de Catalunya. Legajos y documentación cartográfica del Plan depositada en el ANC.

ORDIS, J., CABOT, J., NOGUERA, J.Mª . y VIDAL, M. (1958): II Dictamen de oposición presentado por la provincia de Gerona en el trámite de vista del expediente administrativo del anteproyecto y proyecto de abastecimiento de Barcelona con aguas del río Ter. Gerona. Diputación Provincial, Cámara Oficial Sindical Agraria y Excmo. Ayuntamiento. PAVÓN, D. (2007): La gran obra hidràulica a les conques de la Muga i del Fluvià: dels projectes a les realitzacions (1850-1980). Tesis doctoral. Dir: Anna Ribas, Institut de Medi Ambient (UdG).

PEDREGAL, B. (2005): Población y planificación hidrológica: análisis internacional comparado de los contenidos sociodemográficos de la planficación hidrológica. Sevilla. Universidad de Sevilla y Junta de Andalucía.

PINEDO, E. (1953): Anteproyecto de regulación de los caudales de la cuenca del río Fluviá. Barcelona. C.H.P.O. Fondo A.C.A., Firma. $n^{\circ}$ 685, caja (u.i.): 58. ANC.

PINEDO, E. (1958): Anteproyecto de la zona regable del río Muga. Barcelona. CHPO. Fondo de Obras Públicas; firma: P-934. AGA.

- Idem (1960): Anteproyecto de la zona regable del río Fluviá.

PINEDO, E. (1956): Proyecto de replanteo del pantano de Boadella. Barcelona. C.H.P.O. Fondo A.C.A., firma. núm. 800, caja (u.i.): 68. ANC

PINEDO, E. (1957): Proyecto del Pantano de Esponellá (en el río Fluviá-Gerona). Barcelona. CHPO. Archivo administrativo del embalse de Boadella.

RIBAS, A. y SAURÍ, D. - eds.- (2002): Canvis socioambientals a l'Alt Empordà (19502000). Girona. Càtedra de Geografia i Pensament Territorial i Institut de Medi Ambient $(\mathrm{UdG})$. 
SÁNCHEZ DE OCAÑA, L. (julio de 1950): Informe del ingeniero director, dentro de GETE, A. (1946), Proyecto de pantano de Boadella. Barcelona. C.H.P.O. Fondo A.C.A., Firma. no 499, caja (u.i.): 44. ANC.

SASTRE, J. (2002): Estudi hidrològic i d'alternatives de la zona regable del marge dret del riu Muga. Barcelona. Direcció General de Desenvolupament Rural i Regs de Catalunya, S.A.

SAURI, D. y del MORAL, L. (2001): «Recent developments in Spanish water policy. Alternatives and conflicts at the end of the hydraulic age». Geoforum, n³2, 351-362.

SERRA, M. (2009): «La Costa Brava: la gestió integral de l'aigua en zona turística». Nota d'Economia. Revista d'economia catalana i de sector públic, nº 93-94, 183-194.

SOCIEDAD GENERAL DE AGUAS DE BARCELONA (1960): Incremento del Consumo. Barcelona. Sociedad General de Aguas de Barcelona, S.A.

SWYNGEDOUW, E. (2007): «Technonatural revolutions: the scalar politics of Franco's hydro-social dream for Spain, 1939-1975». Transactions of the Institute of British Geographers, $\mathrm{n}^{\mathrm{o} 32,}$ 9-28.

TUTAU, J. (1888): Medios de levantar la agricultura del Ampurdán de su postración. Barcelona. Tipo-litografia de los suc. de N. Ramírez y $\mathrm{C}^{\mathrm{a}}$.

VEHÍ, M., BRUSI, D., PALLÍ, Ll. y ROQUÉ, C. (1996): Hidrografia (hoja nº9), Cartografia temàtica de les terres de Girona, E1:212.765. Universitat de Girona y Diputació de Girona.

VENTURA, M. (2004): Conflictes socioeterritorials i participació pública en la gestió de l'aigua de la conca del riu Muga (Alt Empordà). Tesi doctoral. Dir.: Anna Ribas, Institut de Medi Ambient (UdG).

VOLTES, P. (1966): Historia del Abastecimiento de Agua de Barcelona. Barcelona. Sociedad General de Aguas de Barcelona.

WORLD COMISSION ON DAMS (2000): Dams and development: a new framework for decision-making: the report of the World Comission on Dams. London. Earthscan: Sterling.

Página web del Instituto Nacional de Estadística; base de datos de población (www.ine.es) 